\title{
Department of Defense Research Funding: Opportunities, Idiosyncrasies, and Risk Analysis
}

\author{
Kurt Preston, Associate Vice Chancellor for Research, \\ University of Nebraska
}

\begin{abstract}
ince World War I the federal government has funded universities to perform research in the defense of the nation. World War I saw the invention of armored vehicles, chemical weapons, and submarine warfare; the broad use of combat aircraft; and the industrial production of explosives through the development of the Fritz Haber process for ammonium nitrate production. As a result of this modernization, American universities and their associated laboratory facilities became involved in defense research.
\end{abstract}

What World War I initiated, World War II perfected. The nation's colleges and universities produced many of the scientists and engineers that would produce radar, sonar, and the first nuclear weapons. By the end of the war, the Endless Frontier was recognized as a frontier requiring full involvement by the defense community.
Over the last 70 years, the leaders of the DoD understood that our universities and the research they produce are key to accomplishing the DoD mission: to protect the American people and advance our nation's interest.

\section{Federal Research Budget}

The federal research budget is a component of federal discretionary spending.

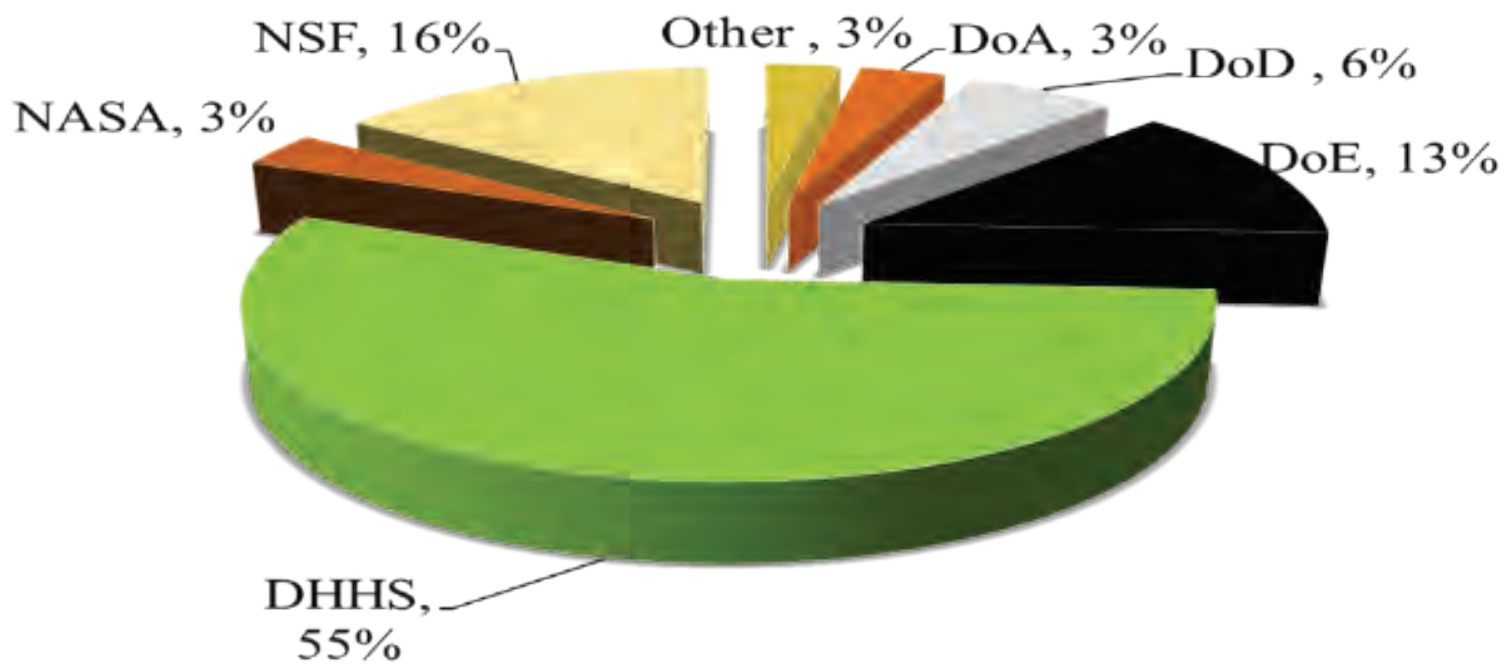

Fiqure 1. Federal Budqet for Basic Research by Aqency 
In Fiscal Year 2011 it totaled $\$ 134$ billion. $51 \%$ of the total budget is allocated to the Department of Defense. As a result, there is often the misplaced assumption that the Department of Defense correspondingly funds about half of the research performed at the nation's research universities. The fact of the matter, which will be described in detail below, is that most of that $51 \%$ is not spent on University related research but on the development of DoD relevant systems.

When the federal budget for basic research is examined by agency, a second picture emerges (Figure 1). Over half of federal basic research is funded by the Department of Health and Human Services (DHHS) through the National Institute for Health (NIH.) The NIH budget takes up $55 \%$ of the nation's federal basic research funding followed by the $\mathrm{Na}$ tional Science Foundation (NSF) at a distant second at $16 \%$. The Department of Defense is not even third on the list. That position is held by the Department of Energy (DoE) at $13 \%$, followed by the Department of Defense (DoD) at 6\%, with the Department of Agriculture (DoA) and the National Aeronautics and Space Administration (NASA) both at 3\% $\%$.

Notwithstanding the relative modest proportion that DoD basic research funding takes in the federal budget, there are some disciplines, such as engineering, where the DoD basic research funding effort comprises a significant portion of its resourcing. Mechanical engineering, electrical engineering, and aeronautical engineering respectively receive $80 \%, 61 \%$, and $35 \%$ of their federal basic research funding through the DoD.
If not in basic research, where does the defense portion of the federal science and technology budget wind up? The Research, Development, Testing, and Evaluation (RDT\&E) budget in fiscal year 2014 totaled $\$ 67.52$ billion or more than about half of the federal science and technology budget. To understand the budget in detail, however, one must be familiar with budget activities which comprise the Planning, Programming and Budgeting system (PPBS), the system which organizes the RDT\&E budget:

Planning, Programming and Budgeting System (PPBS), Budget Activitiesiii

Budget Activity 1, Basic Research. Basic research is systematic study directed toward greater knowledge or understanding of the fundamental aspects of phenomena and of observable facts without specific applications towards processes or products in mind. It includes all scientific study and experimentation directed toward increasing fundamental knowledge and understanding in those fields of the physical, engineering, environmental, and life sciences related to long-term national security needs. It is farsighted high payoff research...

Budget Activity 2, Applied Research. Applied research is systematic study to understand the means to meet a recognized and specific need. It is a systematic expansion and application of knowledge to develop useful materials, devices, and systems or methods. It may be oriented, ultimately, toward the design, development, and improvement of prototypes and new processes to meet general mission area requirements. Applied research may translate promising basic research into solutions for broadly defined military needs, short of system development...

Budget Activity 3, Advanced Technology Development (ATD). This budget activity includes development of subsys- 
tems and components and efforts to integrate subsystems and components into system prototypes for field experiments and/or tests in a simulated environment. ATD includes concept and technology demonstrations of components and subsystems or system models. The models may be form, fit and function prototypes or scaled models that serve the same demonstration purpose. ... this category do not necessarily lead to subsequent development or procurement phases, but should have the goal of moving out of Science and Technology (S\&T) and into the acquisition process within the future years defense program (FYDP). Upon successful completion of projects that have military utility, the technology should be available for transition.

Budget Activity 4, Advanced Component Development and Prototypes (ACD\&P). Efforts necessary to evaluate integrated technologies, representative modes or prototype systems in a high fidelity and realistic operating environment are funded in this budget activity. The ACD\&P phase includes system specific efforts that help expedite technology transition from the laboratory to operational use. Emphasis is on proving component and subsystem maturity prior to integration in major and complex systems and may involve risk reduction initiatives...

Budget Activity 5, System Development and Demonstration (SDD). SDD programs...are conducting engineering and manufacturing development tasks aimed at meeting validated requirements prior to full-rate production... Prototype performance is near or at planned operational system levels. Characteristics of this budget activity involve mature system development, integration and demonstration..., and conducting live fire test and evaluation (LFT\&E) and initial operational test and evaluation (IOT\&E) of production representative articles...

Budget Activity 6, RDT\&E Management Support. This budget activity includes research, development, test and evaluation efforts and funds to sustain and/or modernize the installations or operations required for general research, development, test and evaluation. Test ranges, military construction, maintenance support of laboratories, operation and maintenance of test aircraft and ships, and studies and analyses in support of the RDT\&E program are funded in this budget activity...

Budget Activity 7, Operational System Development. This budget activity includes development efforts to upgrade systems that have been fielded or have received approval for full rate production and anticipate production funding in the current or subsequent fiscal year.

Of the seven activities, it is only in Budget Activity 1 that universities are generally funded. Most often they will be funded from the Army Research Office (ARO), the Air Force Office of Scientific Research (AFOSR), the Office of Naval Research (ONR), or the Defense Advanced Research Projects Agency (DARPA.) The funding will come almost exclusively in the form of grants to the Universities awarded through Broad Agency Announcements (BAAs).

Broadly speaking there are three types of BAAs. The first type is the annual broad agency announcement which describes the research interest of the respective offices and their program managers. For the faculty member pursuing DoD research funding for the first time, the annual broad agency announcement is a critical document to review before contacting the program manager in their respective discipline.

Program managers take great care in crafting the program descriptions found in annual broad agency announcements because there are two inherent mutually exclusive goals in their message. On the 
one hand, the program manager would like to describe the program in sufficiently narrow terms so that a practitioner in the discipline will understand the technical goals and objectives in some detail. On the other hand, the program manager seeks to describe their program in a broad manner that practitioners with unique approaches to relevant technical problems will be encouraged to submit their ideas.

The second type of BAA is one that is topic specific. It is difficult to predict when the topic specific broad agency announcement may be posted to grants.gov or at agency websites. The topic announcements often result from internal discussions in which senior leaders in the

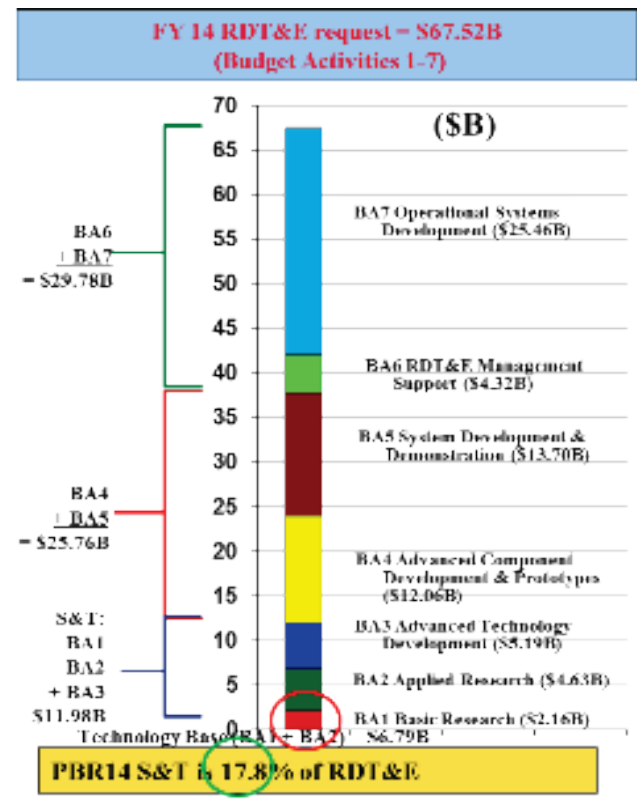

The third and final type of broad agency announcement is the recurring announcement which, as the name implies, is advertised at set intervals, often annually. The Defense University Research Instrumentation Program (DURIP) announcement is an example of an annually recurring announcement. It is often released to the public in the fall, September or October, with winners announced in February or March just before funding from the new annual budget is released to the research offices.

Although Budget Activity 1, basic research funding, is the most common type of funding received by colleges and universities, it represents but a small portion of DOD research funding.

Figure 2 describes the budget re-

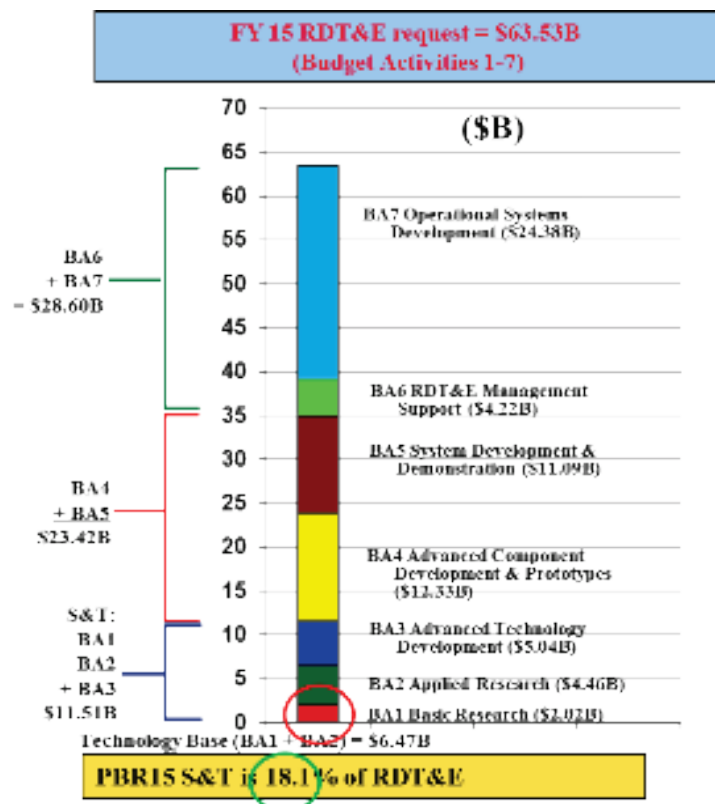

Figure 2: DoD FY 2014 and 2015 RDT\&E Budget Request Comparison ${ }^{i v}$

DoD science and technology enterprise determine that a particular topic area warrants extraordinary focus due to rapid advances in the discipline, perceived technological risk, or a myriad of other factors. quested by the President and submitted to Congress for DoD RDT\&E budget in fiscal years 2014 and 2015. In both years, the RDT \&E budgets were approximately $\$ 65$ billion with basic research receiving 
the smallest portion (red block and circle), approximately $\$ 2$ billion. The largest proportion in both years went to operational system development, Budget Activity 7. Also noteworthy in Figure 2 is the observation that science and technology funding, which includes budget activities one through three, proportionally increased from FY2014 to 2015 . One interpretation of this increase is that it reflects the intent of the senior leadership to avoid an erosion of basic and applied research funding in the face of a very difficult budgetary climate.

Drilling further into the budget, Figure 3 provides a breakout of the science and technology funding across the "Services" (the Army, the Air Force, and Navy), DARPA, other agencies, and the Office of the Secretary of Defense (OSD.) DARPA possesses the largest overall science and technology budget at $\$ 2.793$ billion; however, the largest single basic research funder is the Navy at \$576 million.
Two Highly Differentiated Funding Modalities

The take away message from examining the DoD RDT\&E budget is that there are two highly differentiated funding modalities. The first modality is the basic research mode in which one finds grants awarded, largely to research universities, through the vehicle of a broad agency announcement (BAA.) In the basic research environment the secret to funding is to propose high risk, high payoff research that creates a scientific foundation for future DoD capabilities. The second modality funds applied research and advanced technology development. In general terms, there is an inverse relationship between involvement by universities and maturity of the technology. The further one departs from basic research, the smaller the proportion of funding is likely to be found going to a college or university.

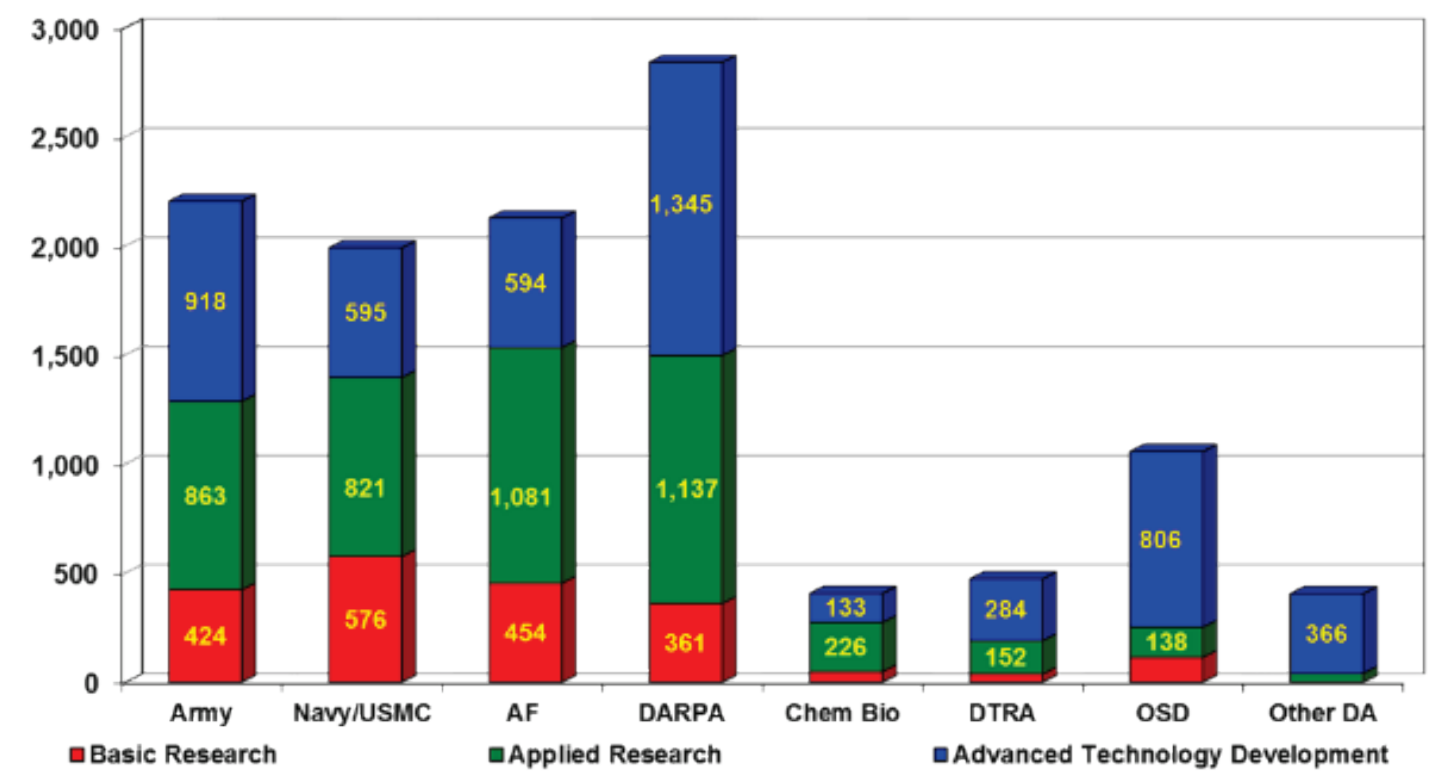

Figure 3. Total FY 2015 Science and Technology request which is $\$ 11.51$ billion. 
There are exceptions to the general rule such as University Affiliated Research Centers. Fourteen UARCs have been established by the DoD to focus on areas of science, engineering, and technology possessing particular importance. UARCs may receive sole-source funding or may compete for science and technology development work across the budget activities. Each UARC is unique in both its core competencies and structure. core competencies found in that university.

\section{Idiosyncrasies}

The take away message for a university research faculty member is that there are two modes of DoD science and technology (S\&T) funding. The first, basic research, is designed to engage the university research faculty member. The second mode, the rest of the (S\&T) funding, rarely benefits university research faculty

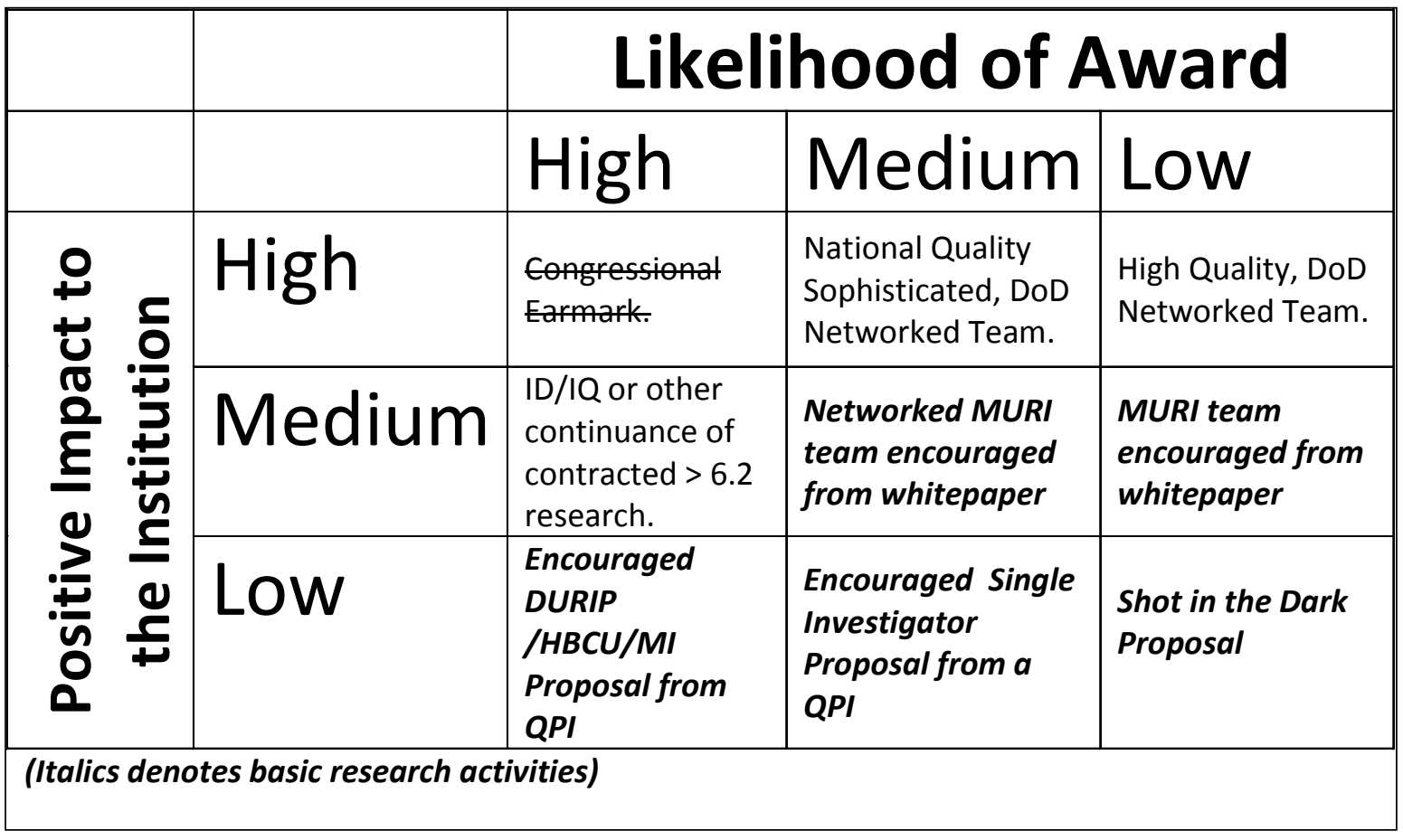

Figure 4: Risk Analysis. The items in italics represent those activities associated with the DOD basic research program and open to individual faculty members or a team of faculty members. The Quality Principal Investigator (QPI) referenced is principal investigator that is performing high-impact research relevant to the DOD and willing to engage the DOD basic research program managers in the discussion of the research interest. Shot in the dark proposals are those in which no attempt has been made to discern the interest of the relevant DOD proqram manaqer.

Some have been in existence since World War II. The newest, the National Strategic Research Institute (NSRI) affiliated with the University of Nebraska and established under the auspices of USSTRATCOM, is two years old. The DoD seeks only to establish UARCs when there is a need that can be uniquely filled by the members unless they lead or find themselves in a team focused on applied DoD problems. It is critical that the faculty member understands in which mode they are pursuing funding. There is no better way for a research faculty member to undermine their proposal to a basic research program manager than to focus on 
applications, talk about what they will demonstrate, or insist that they know how to improve a system. Applications, demonstrations, and systems are all outside the realm of basic research in the DoD context.

\section{Competitive Environment}

At the university institutional level, the question then becomes where does DoD research funding fit into a university's overall strategic and operational planning, especially when this planning is occurring in uncertain times. The answer to this question comes from risk analysis. Since proposal development is a resource intensive process, the institution must balance the potential for positive impact against the likelihood of successful award.

Figure 4 provides a simple initial approach to such risk analysis. In the past, congressional earmarks were probably the awards which possessed the highest potential to produce a positive impact at the institution and the highest likelihood of award. Even in their heyday, however, congressional interest or earmark projects were a very small fraction of total basic or applied research budget. Today, absent earmarks, the highest likelihood of producing a positive impact at the institution are the development of sophisticated, networked teams of national quality researchers performing research of interest to the DoD. These teams must integrate university researchers and corporate technology developers to provide DoD technology development pathways. These are the types of teams that are often funded in DARPA efforts.
Networked teams are also critical for success in pursuing Multidisciplinary University Initiative (MURI) projects. In the case of a MURI, the teams are generally academic researchers networked across disciplines and institutions. At approximately $\$ 1.25$ to $\$ 2.5$ million per year, however, MURI's are insufficient to form the foundation for an institution's research program. They certainly are welcome and important for an individual faculty member or teams of faculty members, but the level of resourcing is such that they are in addition to, but not the basis of, a university research enterprise.

An opportunity with the potential for medium positive impact to the institution and a high likelihood of award is for the university to be part of the team contracted for research beyond basic research (BA 2 [aka 6.2] or higher). These applied research efforts, however, can pose significant challenges for the university. These challenges often include high administrative burden and intellectual constraints that come from export control and other restrictions when working on DoD applied research projects.

\section{Conclusion}

DoD research funding has a place in planning for future research in public universities in uncertain times. However, the DoD is not the principal source of research dollars to colleges and universities. It is a distant fourth behind NIH, NSF, and DOE. Absent a unique relationship created by either a UARC or other contract, it is unlikely that DoD research funding would form the basis 
for funding the University research enterprise. Nonetheless, the DoD basic research program provides a vehicle for university principal investigators to be involved in the defense of the nation through their research activities.

\section{References}

i 50 USC 1 - Council of National Defense.

ii National Science Foundation, National Center for Science and Engineering Statistics. 2012. Federal Funds for Research and Development: Fiscal Years 2009-11. Detailed Statistical Tables NSF 12-318. Arlington, VA. Available at: http://www.nsf.gov/statistics/nsf12318/. iii "Definitions of Research and Development: An Annotated Compilation of Official Sources", Available at National Science Foundation, http://www.nsf.gov/statistics/randdef/fedgov.cfm.

iv "Mr. Bob Baker Deputy Director, Plans \& Programs, Assistant Secretary of Defense (Research \& Engineering). Fiscal Year 2015 President's Budget Request for the DoD Science \& Technology Program. April 8, 2014. Available at http://www.defenseinnovationmarketplace.mil/resources/FY14DoDSTBudgetRequestPresentation.pdf. 